\title{
A Study of the Effect of Fusion of Multi-sensor and Cutting Chip Color on the Lifetime of Cutting Tool Coated with TiAlN
}

\author{
Shao-Hsien Chen ${ }^{1 *}$ and Min-sheng Gao ${ }^{2}$ \\ 1 The Graduate Institute of Precision Manufacturing, National Chin-Yi University of Technology, \\ No.57, Sec. 2, Zhongshan Rd., Taiping Dist., Taichung 41170, Taiwan \\ 2 Department of Mechanical Engineering, National Chin-Yi University of Technology, \\ * Correspondence: e6036@ncut.edu.tw
}

\begin{abstract}
In the mold machining process, the cutting tool is worn with machining time, thereby affecting the surface accuracy, leading to poor workpiece dimensions, even fracture. At present, many studies have used multiple sensors to detect the machining conditions of cutting tool and workpiece, including indirect measurement method and direct measurement method. The indirect measurement method, which has been studied widely, mainly uses sensors to capture signals for subsequent data analysis; the direct measurement method mainly analyzes the state of cutting shear zone. Due to the cut-in of cutting tool in the machining process, the workpiece is dislocated rapidly, generating considerable amount of heat, which is transferred to the chips, inducing color change on the surface of chips. Many engineers with machining experience often judge the machining state and tool life according to the chips. The engineers' experience is digitized in this study, and indirect measuring sensors are used to predict the tool life, so as to attain the objective for smart manufacturing, the average percentage error of MAPE using single vibration and voltage eigenvalues as input features is $10 \%$, the voltage signal characteristic values and vibration signal characteristic values are combined. Finally, the chip surface chromaticity eigenvalue is combined with signal characteristic value. The average prediction error of BP-LM method is $7.85 \%$, the average prediction error of GRNN method is $6.59 \%$. Therefore, when the eigenvalue of chip surface chromaticity is added to the prediction result, it can enhance the accuracy of cutting tool wear value prediction more effectively than single sensor signal characteristic value.
\end{abstract}

Keywords: cutting tool wear; chip color; color correction , Multi-sensor

\section{Introduction}

The direct measurement method mainly measures the state of cutting shear zone. The cutting tool dislocates the workpiece rapidly in the machining process, generating a large amount of heat, which is transferred to the chips, inducing color change on the chip surface. Many engineers with machining experience often judge the machining state and tool life according to chips. This study digitized engineers' experience is digitized, and used indirect measuring sensors to predict the tool life. The indirect sensors were accelerometer and current sensor. The chip surface chromaticity characteristic and multi-sensor characteristic in machining were fused to identify the status of cutting tools. The state with the same trend was confirmed and selected after classification and analysis processing of data. This study used BP-LM neural network model to predict the TiAlN coated cutting tool wear value, combined with the characteristic value of vibration signal, characteristic value of voltage signal and characteristic value of chip surface chromaticity. In addition, the GRNN neural network model was used to predict the TiAlN coated cutting tool wear value. The characteristic value of vibration signal, characteristic value of voltage signal and characteristic value of chip surface chromaticity were combined.

\section{Research Purposes and Motives}


Halim et al. [1] analyzed the relations of tool life, cutting tool wear mode and chip morphology. The experimental results showed that the low temperature $\mathrm{co}^{2}$ cooling system could cool the cutting area and reduce the cutting temperature to $80 \%$ more effectively than dry cutting. Therefore, in comparison to dry cutting, the low temperature cutting can mitigate cutting tool wear, and can prolong the tool life up to $70.8 \%$.

Ihsan et al. [2] studied the relation between cutting parameters and chip surface temperature in the lathe machining of AISI 1117 steel. The chip surface temperature changes under such three parameters as cutting speed, feedrate per revolution and depth of cut were compared. The experimental results showed that the temperature of chips rose as the cutting speed, feedrate and depth of cut increased. The cutting speed and depth of cut were the significant factors in the chip surface temperature change.

Li et al. [3] discussed feature selection and classification method, and used the current signals of spindle motor to diagnose the drilling process. The non-invasive Hall effect sensor was used to measure the motor current. The wavelet coefficients of current signal were calculated first, and the subset of these coefficients was selected as initial diagnostic characteristic based on their ability to identify each pair of fault categories. The method used nonlinear RPNN for paired feature classification. The experimental data proved that the average success rate of classification result of the proposed method was $93 \%$.

Kim et al. [4] discussed a monitoring method based on neural network and spindle motor power sensor, so as to test the chip processing state in drilling. If the chip flow was poor in the drilling process, the fluctuations of static component and dynamic component of drilling torque increased greatly. Therefore, the two components contributed to monitoring the chip processing state in the drilling process. The spindle motor power was tested by AC spindle motor driving system, and the drilling torque could be measured indirectly, and the difference of square/average value, mean absolute deviation and gradient could be measured according to the spindle motor power as feature vectors.

Sudhansu et al. [5] used the parameter data of surface roughness, cutting tool wear and chip morphology of cutting AISI 4340 steel to estimate the cost. The ANOVA showed that the dominant parameters influencing the surface roughness were the feedrate per revolution, followed by cutting speed. The surface roughness value increased with the feedrate per revolution, and the cutting speed was in inverse relation.

Ning et al. [6] analyzed the chip color to judge the cutting temperature in the highspeed end milling of die steel AISI H13. The study used a ball cutter for high-speed end milling at 10,000-30,000 rpm. The color of chips and temperature at different spindle speeds and depths of cut. The result shows that the cutting temperature rises as the spindle speed and depth of cut increase.

Previous studies on cutting tool wear monitoring mostly used the physical signals of sensors related to cutting tool wear to identify the condition of cutting tool wear according to the mapping correlation between the characteristic values of the original signal and the cutting tool wear, such as motor power and current method, vibration monitoring method, acoustic emission monitoring method, cutting force monitoring method and so on. This study used the color change on the chip surface, accelerometer and current for prediction, there is no related study so far [14-16].

\section{Cutting principle and wear}

\subsection{Cutting tool wear}

In general studies of cutting, the methods to use and make tool life mostly adopt Taylor tool life equation for modeling. In 1906, Taylor proposed the relationship between tool life and cutting speed. The relationship between cutting speed (V) and tool life (T) can be expressed as the following equation [7][8]:

$$
\mathrm{VT}^{\mathrm{n}}=\mathrm{C}
$$

where V: cutting speed (m/min), T: tool life, i.e. actual cutting time (min), n: the index is determined according to the cutting tool and workpiece material conditions, $\mathrm{C}$ : constant 
in machining, besides cutting speed, the machining parameters include feed per tooth and cutting depth. If all the machining parameters are considered in the tool life equation, a complete tool life equation can be obtained and expressed as follows:

$$
\mathrm{Vx} \mathrm{T}^{\mathrm{n}} \mathrm{xf}_{\mathrm{z}}^{\mathrm{a}} \mathrm{xap}^{\mathrm{b}}=\mathrm{C}
$$

where V: cutting speed (m/min), T: tool life, i.e. actual cutting time ( $\mathrm{min}), \mathrm{n}$ : the index is determined according to cutting tool and workpiece material conditions, $\mathrm{f}_{\mathrm{z}}$ : feed per tooth ( $\mathrm{mm} /$ tooth), a: the index is determined according to cutting tool and workpiece material conditions, ap: cutting depth $(\mathrm{mm}), \mathrm{b}$ : the index is determined according to cutting tool and workpiece material conditions, C: constant

\subsection{Die steel SKD61 difficult to cut}

The SKD61 is hot-work tool steel, with alloying elements such as Chromium (Cr), Molybdenum (Mo) and Vanadium (V), so it has favorable ductility, wear resistance and resistance to high temperature fatigue. The composition and physical characteristics of SKD61 material are shown in table 1, suitable for long-term operation in hot environment. The higher the hardness of mold is, the longer is the service life of mold, it can bear sudden temperature change, and it is unlikely to deform, so the die steel material is universally used by the circle. This material is applicable to $\mathrm{Al}, \mathrm{Mg}, \mathrm{Zn}$ and $\mathrm{Cu}$ alloy compression molds. The hand tools are usually used for grooving tool and hot forging, hot working reamers, guillotine and hot working forging dies, plastic pattern dies, hot bolt molds and hot working tools. Therefore, this study used SKD61 as the material for machining experiments.

Table 1. Physical characteristics of die steel SKD61 [9].

\begin{tabular}{cccc}
\hline Physical property & \multicolumn{3}{c}{ Temperature range } \\
\hline Thermal expansion coefficient & $20-100^{\circ} \mathrm{C}$ & $20-250^{\circ} \mathrm{C}$ & $20-500^{\circ} \mathrm{C}$ \\
\cline { 2 - 4 }$\left(\frac{10^{-6}}{\mathrm{~K}}\right)$ & 10.5 & 11.3 & 12.1 \\
\hline Thermal conductivity & $20^{\circ} \mathrm{C}$ & $250^{\circ} \mathrm{C}$ & $500^{\circ} \mathrm{C}$ \\
\cline { 2 - 4 }$(\mathrm{W} / \mathrm{mK})$ & 23 & 25 & 27 \\
\hline E-modulus & $21^{\circ} \mathrm{C}$ & $250^{\circ} \mathrm{C}$ & $500^{\circ} \mathrm{C}$ \\
\cline { 2 - 4 }$\left(\frac{\mathrm{KN}^{2}}{\mathrm{~mm}}\right)$ & 210 & 195 & 172 \\
\hline
\end{tabular}

\subsection{Chip color and cutting temperature}

In the cutting processes, the causes of cutting heat are distributed over three main regions: the chips are discharged from the tool face due to workpiece material exfoliation, shearing and deformation, and the frictional contact surface between tool flank and workpiece material induces high temperature condition of workpiece, chips and cutting tool. If the cutting parameter conditions are appropriate, when the chip thickness decreases, the chips are heated up rapidly under the effect of this cutting heat, and it can be known from the color change or the pyrophoric behavior of chips. However, the chips are cooled rapidly in the air after they are cut off the parent material, this phenomenon makes the chips form oxidation film of different colors on the surface, as shown in figure 1, the color of this oxidation film is influenced by the oxidation film thickness (d), refractive index (n) and absorption coefficient $(\mathrm{k})$ of oxidation film and parent material, as shown in figure 2. The color of chips during machining changes in the order of light yellow $\rightarrow$ yellow brown $\rightarrow$ brown $\rightarrow$ purple $\rightarrow$ dark purple or dark blue $\rightarrow$ blue $\rightarrow$ light blue $\rightarrow$ bluish green $\rightarrow$ greenish yellow $\rightarrow$ dark red .[10] 


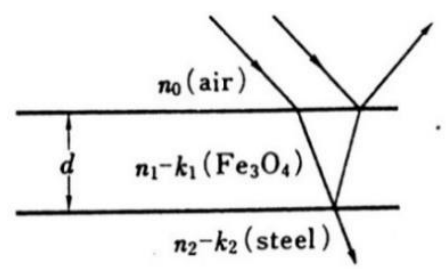

Figure 1. Oxidation film model [10].

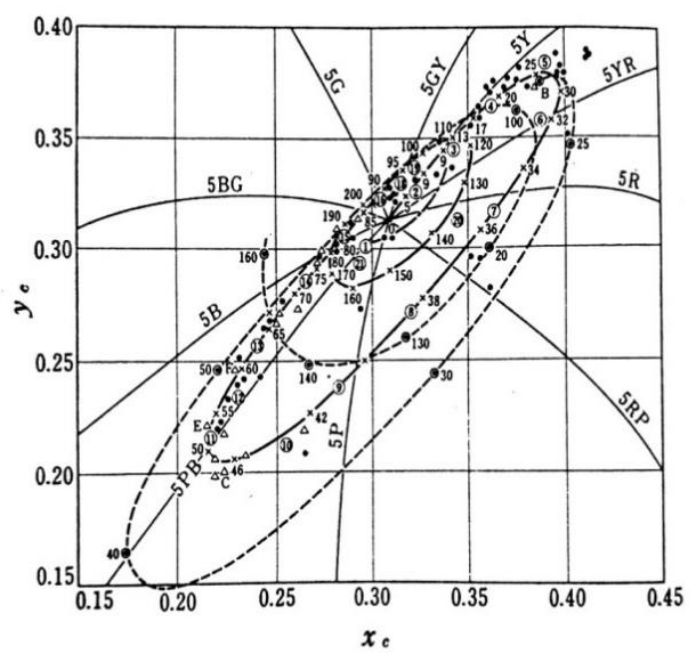

Figure 2. Chromaticity diagram [10].

The figure 2 is the graph of relation between chip oxidation film thickness and chromaticity coordinate points, the graph of relation displays annular solid lines, the lines spread radially from the center represent $Y$ yellow, $R$ red, $P$ purple, B blue and G green hues respectively.

\section{Measurement equipment development and modeling}

The chip color and measurement equipment data are mainly transformed from the chromatic values such as RGB values, $X Y Z$ tristimulus values and $x y$ chromatic values. In terms of the display, the system receives electronic signals, the colors are mixed according to the signal intensity, and the corresponding colors are obtained and displayed on the screen, so the color value transformation of display is different from the mathematical computation model of colorimetry. The process of display color space transformation is detailed below. The process of color space transformation of display system is shown in figure 3. [4]

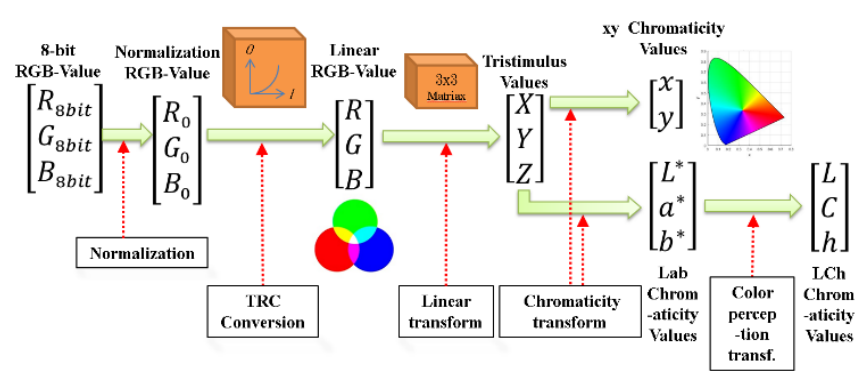

Figure 3. Display system color transformation process [11][17].

The main process of chip color and measurement equipment data creation is described below. 


\section{Step-1. Normalization}

The initial input color signals of display are [R8-bit G8-bit B8-bit] 8-bit RGB signal values, the numerical range of three primary colors is $0 \sim 255$, transformed to $\left[R_{0} G_{0} B_{0}\right]$ normalized RGB signal values.

$$
I_{0}=\frac{I}{255}
$$

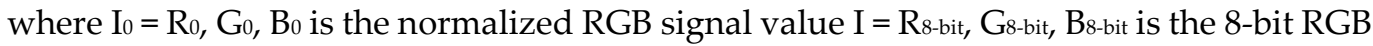
signal value

\section{Step-2. TRC Transformation}

The TRC is the abbreviation for Tone Reproduction Curve, representing the relationship between display input signal value and brightness. The normalized RGB values $\left[\mathrm{R}_{0}\right.$ $\mathrm{G}_{0} \mathrm{~B}_{0}$ ] are transformed by this TRC into linear RGB values [R G B]. In a general way, the display uses $\gamma$ value to represent the tone relationship between the normalized RGB values and linear RGB values, the $\gamma$ value varies with the display specification, generally 1.8 2.4.

$$
\begin{aligned}
& \mathrm{R}=\left(R_{0}\right)^{\gamma_{R}} \\
& \mathrm{G}=\left(G_{0}\right)^{\gamma_{G}} \\
& \mathrm{~B}=\left(B_{0}\right)^{\gamma_{B}}
\end{aligned}
$$

where $\mathrm{R}, \mathrm{G}$ and $\mathrm{B}$ are linear RGB signal values

$\gamma_{R}, \gamma_{G}, \gamma_{B}$ are the $\gamma$ values corresponding to $\mathrm{R}, \mathrm{G}$ and $\mathrm{B}$

\section{Step-3. Linear Transformation}

The linear transformation is a step of transforming linear RGB values [R G B] to XYZ tristimulus values [XY Z], a $3 \times 3$ matrix is calculated in the process. The $3 \times 3$ transformation matrix varies with the display of different standards, the standards of different kinds of displays will be detailed in Section 2.6.

$$
\left[\begin{array}{l}
X \\
Y \\
Z
\end{array}\right]=M\left[\begin{array}{l}
R \\
G \\
B
\end{array}\right]
$$

where $\mathrm{X}, \mathrm{Y}$ and $\mathrm{Z}$ are tristimulus values and $\mathrm{M}$ is $3 \times 3$ linear transformation matrix

\section{Step-4. Chromaticity transformation}

The XYZ tristimulus values [X Y Z] can be transformed to xy chromatic values [x y] according to Eq. 2-15 as required and displayed in the CIE xy chromaticity diagram, or transformed to $\mathrm{L}^{*} \mathrm{a}^{*} \mathrm{~b}^{*}$ chromatic values $\left[\mathrm{L}^{*} \mathrm{a}^{*} \mathrm{~b}^{*}\right.$ ] according to Eq. 2-15 and displayed in CIE LAB color space diagram.

$$
\begin{gathered}
\mathrm{L}^{*}=116 \mathrm{f}\left(\frac{Y}{Y_{n}}\right)-16 \\
\mathrm{a}^{*}=500\left[\mathrm{f}\left(\frac{X}{X_{n}}\right)-\mathrm{f}\left(\frac{Y}{Y_{n}}\right)\right] \\
\mathrm{b}^{*}=500\left[\mathrm{f}\left(\frac{Y}{Y_{n}}\right)-\mathrm{f}\left(\frac{Z}{Z_{n}}\right)\right] \\
\mathrm{f}\left(\frac{I}{I_{n}}\right)=\left(\frac{I}{I_{n}}\right)^{\frac{1}{3}}, \text { if }\left(\frac{I}{I_{n}}\right)>0.008856
\end{gathered}
$$




$$
\mathrm{f}\left(\frac{I}{I_{n}}\right)=7.787\left(\frac{I}{I_{n}}\right)+\frac{16}{116}, \text { if }\left(\frac{I}{I_{n}}\right) \leq 0.008856
$$

where I / $\mathrm{I}_{\mathrm{n}}=\mathrm{X} / \mathrm{X}_{\mathrm{n}}=\mathrm{Y} / \mathrm{Y}_{\mathrm{n}}=\mathrm{Z} / \mathrm{Zn}_{\mathrm{n}}$

$X, Y$ and $Z$ are tristimulus values of object

$X_{n}, Y_{n}$ and $Z_{n}$ are tristimulus values of reference white, the tristimulus values vary with different kinds of light sources

\section{Step-5. Color Perception Transformation}

This step transforms $\left[\mathrm{L}^{*} \mathrm{a}^{*} \mathrm{~b}^{*}\right]$ of CIE LAB color space to color perception attribute value of [L C h], L, $C_{a b^{*}}$ and $h_{a b}$ represent lightness, chroma and hue respectively.

$$
\begin{gathered}
C_{a b^{*}}=\sqrt{\left[\left(a^{*}\right)^{2}+\left(b^{*}\right)^{2}\right]} \\
h_{a b}=\tan ^{-1}\left(\left|\frac{b^{*}}{a^{*}}\right|\right)
\end{gathered}
$$

where the $h_{a b}$ computing $\mathrm{a}^{*}$ and $\mathrm{b}^{*}$ will have different combinations of positive values or negative values, the absolute value of $\left(\frac{b^{*}}{a^{*}}\right)$ is taken, and then the appropriate angle is worked out according to its coordinates in the quadrant.

\subsection{Machining experiments}

According to the recommended values of cutting parameters in the technical information of Mitsubishi tool catalog [12], for the TiAlN coated carbide blade material, the cutting speed $(\mathrm{m} / \mathrm{min})$ recommended as 50 to $120(\mathrm{~m} / \mathrm{min})$, the feed per tooth $(\mathrm{mm} / \mathrm{tooth})$ is recommended as $\leq 0.2(\mathrm{~mm} /$ tooth $)$. For the TiAlN coated carbide blade material, the depth of cut $(\mathrm{mm})$ is recommended as $\leq 0.5(\mathrm{~mm})$. The experimental calculation refers to Taylor's formula, the machining parameter configuration is fixed and adjusted, so as to implement the process from initial wear to acute wear of cutting tool. This study used a machining center for milling, where the experimental equipment as shown in figure 4 . The 3 axes, X, Y, and Z, moved on travel of $450 \mathrm{~mm}, 300 \mathrm{~mm}$, and $360 \mathrm{~mm}$ respectively. The feed velocity was from 36,000 to $48,000 \mathrm{~mm} / \mathrm{min}$, and the maximum revolution of the main spindle was 10,000 rpm. 

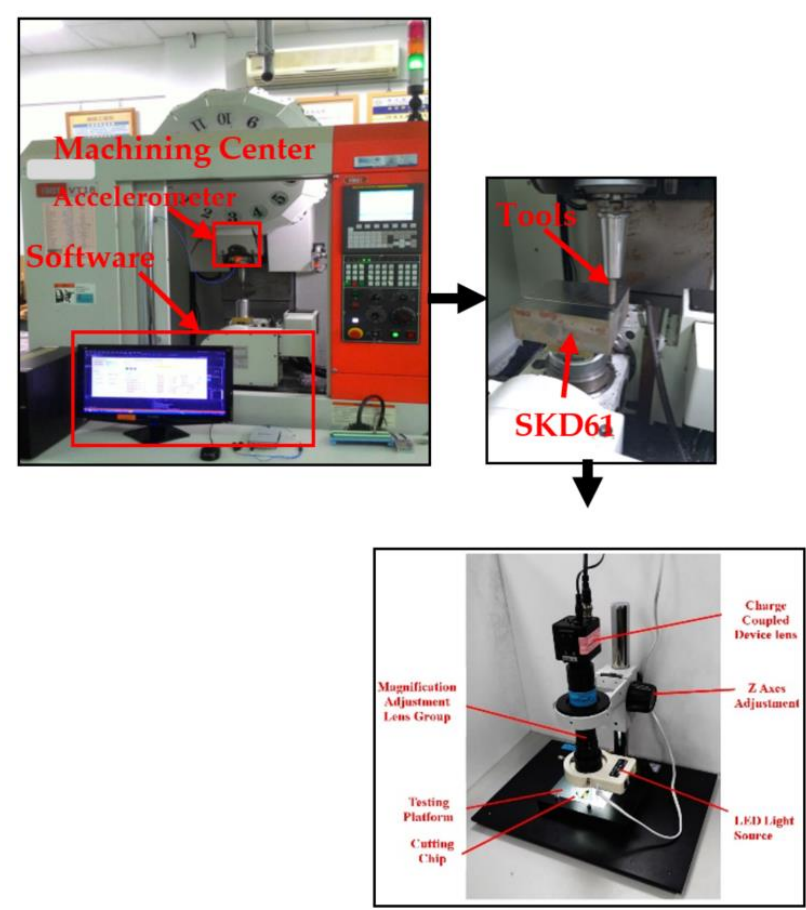

Figure 4. the experimental equipment.

\subsection{Color information reading and correction}

If the chromatic color correction technique is used in industrial camera equipment, the adaptive light source color correction system must build individual correction transformation models under different light source settings, for example, to transform RGB into CIEXYZ, related matrix parameters shall be established by linear relationship for operations, the fundamental purpose is to make the filmed color image closer to the real color image. 7 shows the color correction process of image capture equipment, as shown in figure 5.

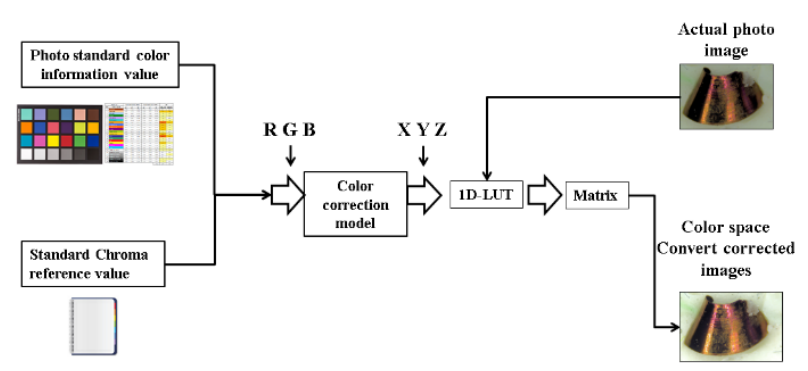

Figure 5. Color correction process of image capture equipment.

The eq.16 transform $R^{\prime} G^{\prime} B^{\prime}$ to the regression equation of color space CIE LAB, and then to the matrix form of eq. 4 , and the $\mathrm{R}^{\prime} \mathrm{G}^{\prime} \mathrm{B}^{\prime}$ values and the CIE LAB standard values attached to the Color Checker Passport color chart are substituted in Eq. 4 to calculate the values of color correction matrix $\mathrm{M}$, the color correction model is built. If the color correction capability is insufficient, the shooting environment is improved till the chromatic aberration grade reaches the target level. Finally, the material chips are shot to obtain the parameters for judging the cutting tool wear.

$$
\begin{aligned}
& \mathrm{L}^{*}=\mathrm{a}_{0}+\mathrm{a}_{1} \mathrm{R}^{\prime}+\mathrm{a}_{2} \mathrm{G}^{\prime}+\mathrm{a}_{3} \mathrm{~B}^{\prime}+\mathrm{a}_{4} \mathrm{R}^{\prime} \mathrm{G}^{\prime}+\mathrm{a}_{5} \mathrm{R}^{\prime} \mathrm{B}^{\prime}+\mathrm{a}_{6} \mathrm{G}^{\prime} \mathrm{B}^{\prime}+\mathrm{a}_{7} \mathrm{R}^{\prime 2}+\mathrm{a}_{8} \mathrm{G}^{\prime 2} \\
& +a_{9} B^{\prime 2}+a_{10} R^{\prime} G^{\prime} B^{\prime}+a_{11} R^{\prime 3}+a_{12} G^{\prime 3}+a_{13} B^{\prime 3} \\
& a^{*}=b_{0}+b_{1} R^{\prime}+b_{2} G^{\prime}+b_{3} B^{\prime}+b_{4} R^{\prime} G^{\prime}+b_{5} R^{\prime} B^{\prime}+b_{6} G^{\prime} B^{\prime}+b_{7} R^{\prime 2}+b_{8} G^{\prime 2} \\
& +b_{9} B^{\prime 2}+b_{10} R^{\prime} G^{\prime} B^{\prime}+b_{11} R^{\prime 3}+b_{12} G^{\prime 3}+b_{13} B^{\prime 3}
\end{aligned}
$$




$$
\begin{aligned}
& \mathrm{b}^{*}=\mathrm{c}_{0}+\mathrm{c}_{1} \mathrm{R}^{\prime}+\mathrm{c}_{2} \mathrm{G}^{\prime}+\mathrm{c}_{3} \mathrm{~B}^{\prime}+\mathrm{c}_{4} \mathrm{R}^{\prime} \mathrm{G}^{\prime}+\mathrm{c}_{5} \mathrm{R}^{\prime} \mathrm{B}^{\prime}+\mathrm{c}_{6} \mathrm{G}^{\prime} \mathrm{B}^{\prime}+\mathrm{c}_{7} \mathrm{R}^{\prime 2}+\mathrm{c}_{8} \mathrm{G}^{\prime 2} \\
& +\mathrm{c}_{9} \mathrm{~B}^{\prime 2}+\mathrm{c}_{10} \mathrm{R}^{\prime} \mathrm{G}^{\prime} \mathrm{B}^{\prime}+\mathrm{c}_{11} \mathrm{R}^{\prime 3}+\mathrm{c}_{12} \mathrm{G}^{\prime 3} \\
& +\mathrm{c}_{13} \mathrm{~B}^{\prime 3}
\end{aligned}
$$

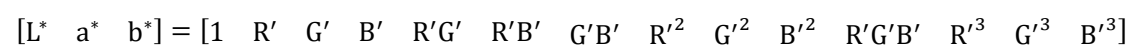

$$
\begin{aligned}
& \times\left[\begin{array}{ccc}
a_{0} & b_{0} & c_{0} \\
a_{1} & b_{1} & c_{1} \\
\vdots & \vdots & \vdots \\
a_{13} & b_{13} & c_{13}
\end{array}\right]
\end{aligned}
$$

\section{Results and Discussion}

\subsection{Wear analysis result of TiAlN coated tips}

This study used three machining experiments, in order to repeat the test. Each group of TiAlN coating is cut 10 times, as shown in Error! Reference source not found.6 7. The correlation of the number of cuttings to the chip morphology and the degree of cutting tool wear is discussed. At the 11th cutting, the degree of wear reaches acute wear, the left front end of chip shape is curled. However, observing the gloss of the chip surface color, from the $2^{\text {nd }}$ to the $7^{\text {th }}$ cutting, the cutting tool wear is in stable cutting status, the chip surface color is purple blue. After the $7^{\text {th }}$ cutting, the degree of cutting tool wear gets in the accelerating wear region, and then at the 8th cutting, the chip surface color turns from purple blue into dark purple blue and dark blue. Finally, at the 11th cutting, the degree of wear reaches acute wear, the chip surface color turns from dark blue into cyan.

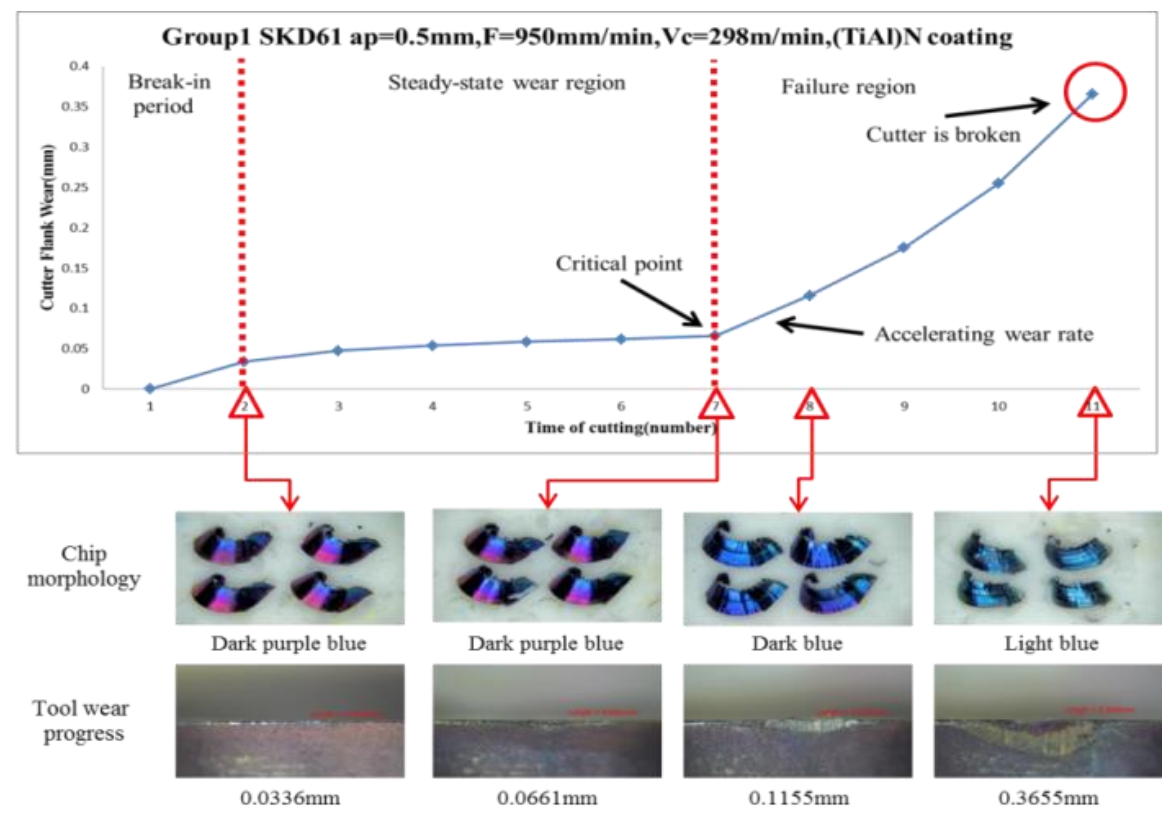

Figure 6. Degree of cutting tool wear and chip morphology of TiAlN coating in Group 1 experiment on dry cutting. 


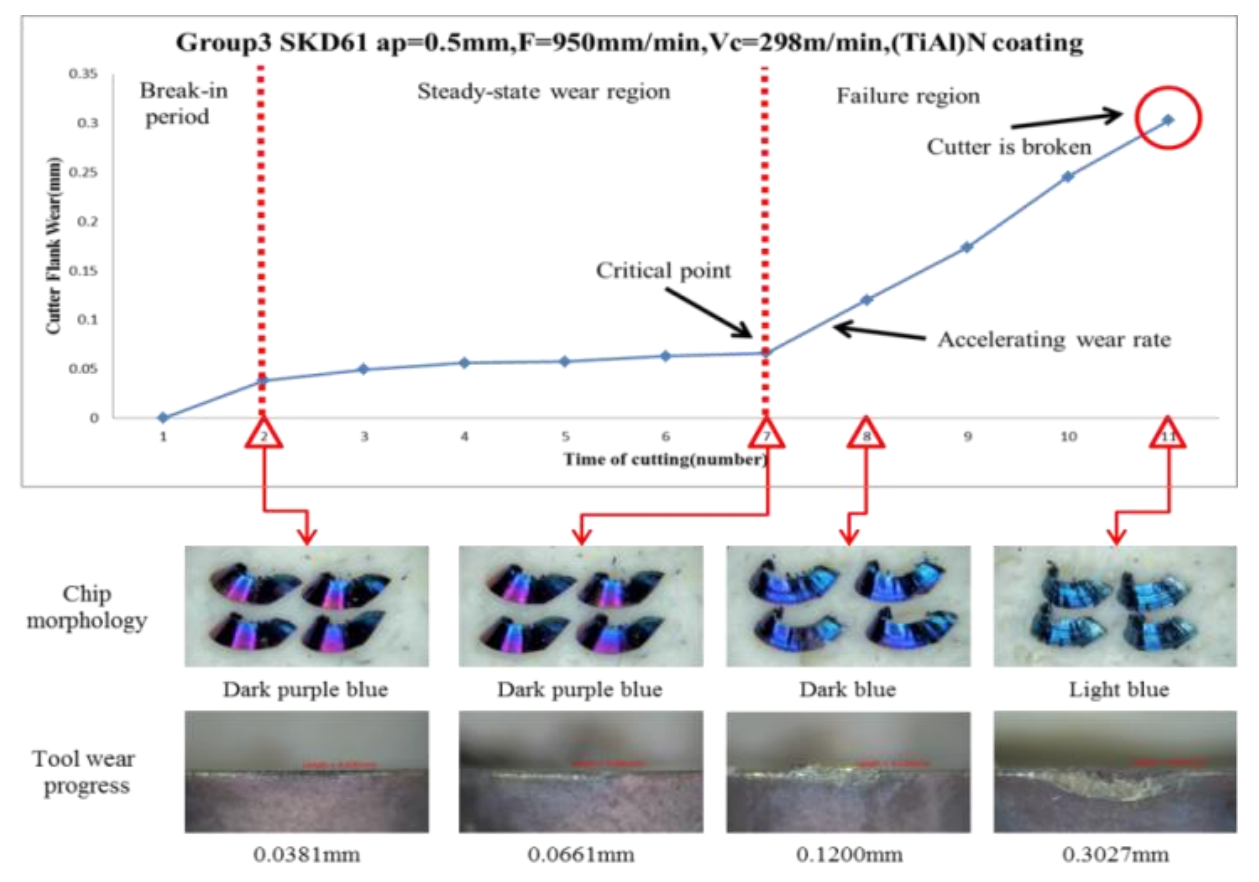

Figure 7. Degree of cutting tool wear and chip morphology of TiAlN coating in Group 3 experiment on dry cutting.

\subsection{Time-frequency domain signal characteristic analysis of voltage and vibration of TiAlN coated tips}

This study uses 23 dimensional feature values for further feature trend analysis, taking the first group of cutting as an example, according to the time-frequency domain characteristic patterns of different combinations in figure 8 9, the global feature values increase obviously with the number of cuttings, meaning the wear state of blade increases with wear, and there is significant coincidence relation between the initial wear state and acute wear state of tool flank wear, so it will be favorable for building the cutting tool wear prediction model of algorithm.

In the frequency-domain signal characteristic analysis of TiAlN coated tips for voltage and vibration, the spindle $Z$ axis and servo $Y$ axis of voltage signals are highly correlated with $1 X$ frequency of $Z$ axis, the $1 X$ frequency of servo $X$ axis is free of obvious regularity, and in the $X, Y$ and $Z$ axes of vibration signals, the 1,2 and $4 X$ frequencies of $X$ axis, $1 X$ frequency of $Y$ axis, the 1, 2, 4 and $6 X$ frequencies of $Z$ axis have higher correlation, the correlation of features is higher than 0.9. From the initial wear to acute wear of cutting tool wear, the characteristic values increase obviously, meaning the characteristic value variation trend matches the physical phenomenon of cutting tool wear trend, so there is corresponding correlation between the frequency-domain signal of voltage and vibration characteristics and cutting tool wear value. 


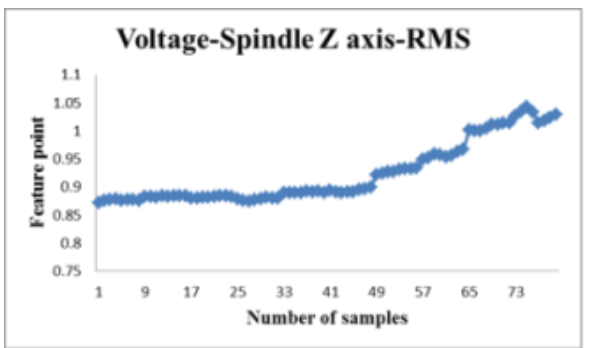

(a)

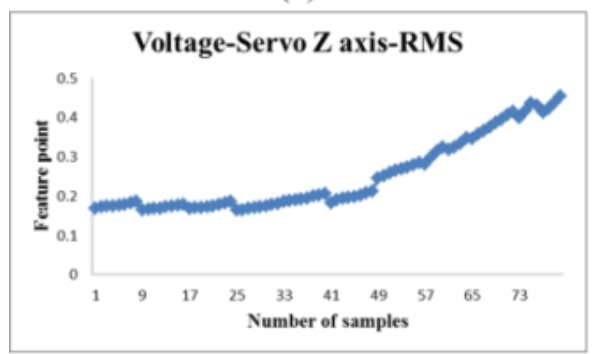

(c)

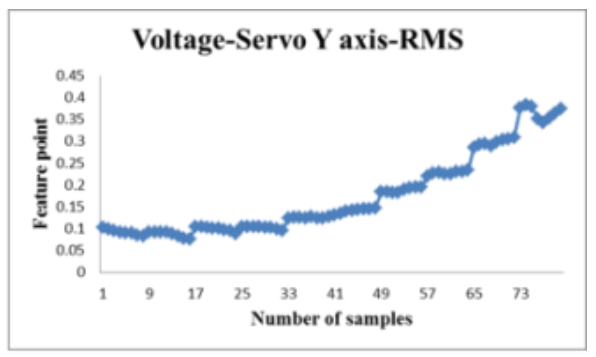

(b)

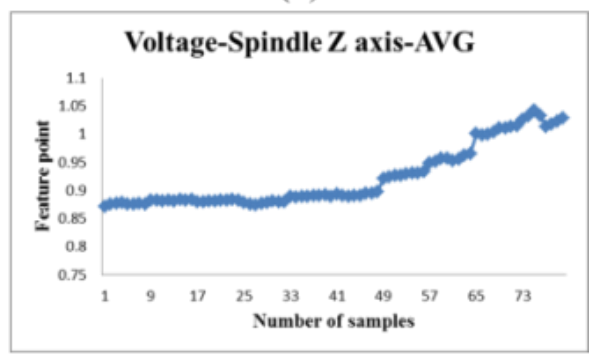

(d)

Figure 8. Sensor time-frequency domain signal characteristic graph of TiAlN coated tips cutting Group 1 (a) voltage-spindle $Z$ axis-RMS (b) voltage-servo $Y$ axis-RMS (c) voltage-servo $Z$ axis-RMS (d) voltage-servo $Z$ axis-AVG.

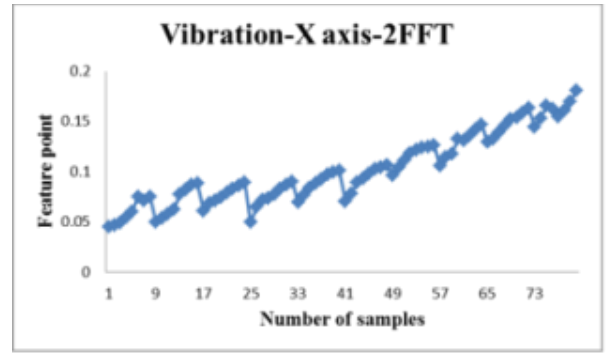

(a)

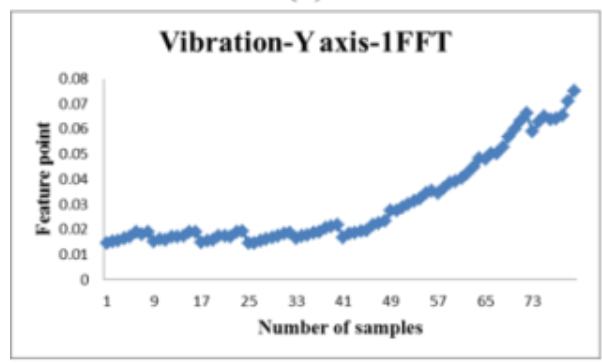

(c)

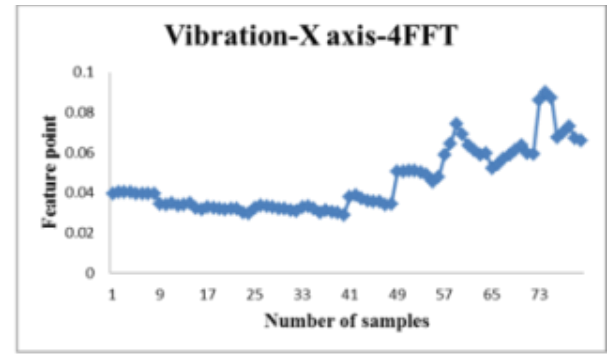

(b)

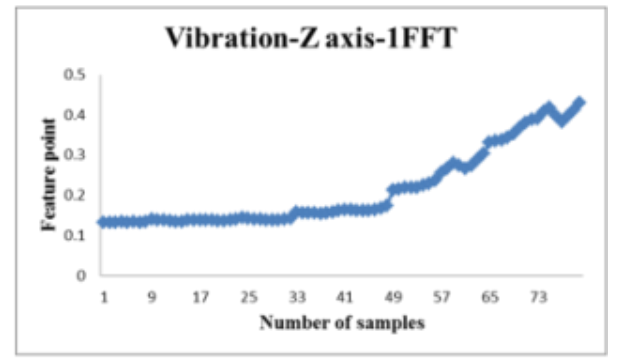

(d)

Figure 9. Sensor time-frequency domain signal characteristic graphs of TiAlN coated tips cutting Group 1 (a) vibration-X axis-2FFT (b) vibration-X axis-4FFT (c) vibration-Y axis-1FFT (d) vibration$\mathrm{Z}$ axis-1FFT.

\subsection{Test and validation results of cutting tool wear prediction model}

The correlation between the carbide blade wear and chip surface chromaticity eigenvalue of three groups of TiAlN coating will be described. Three phenomena can be observed in figure 10 11. First of all, No. 2, 7, 8 and 11 cuttings are selected to observe the trend of chip surface chromaticity. It is observed that as the cutting tool wear value increases, the ranges of chip surface chromaticity $X$ and $Y$ characteristic values shift clockwise. Secondly, when the cutting tool turns from initial unworn state into acute wear state, the color change trend of chip surface chromaticity eigenvalue is purple@purple blue @ blue @cyan. Thirdly, at the 7th and 8th cutting, figure 12 shows the aliasing of chip 
chromaticity $X$ characteristic value and $Y$ characteristic value, and the turning point from stable cutting status to accelerating wear of the degree of cutting tool wear, the cutting tool wear has reached the unstable state region.

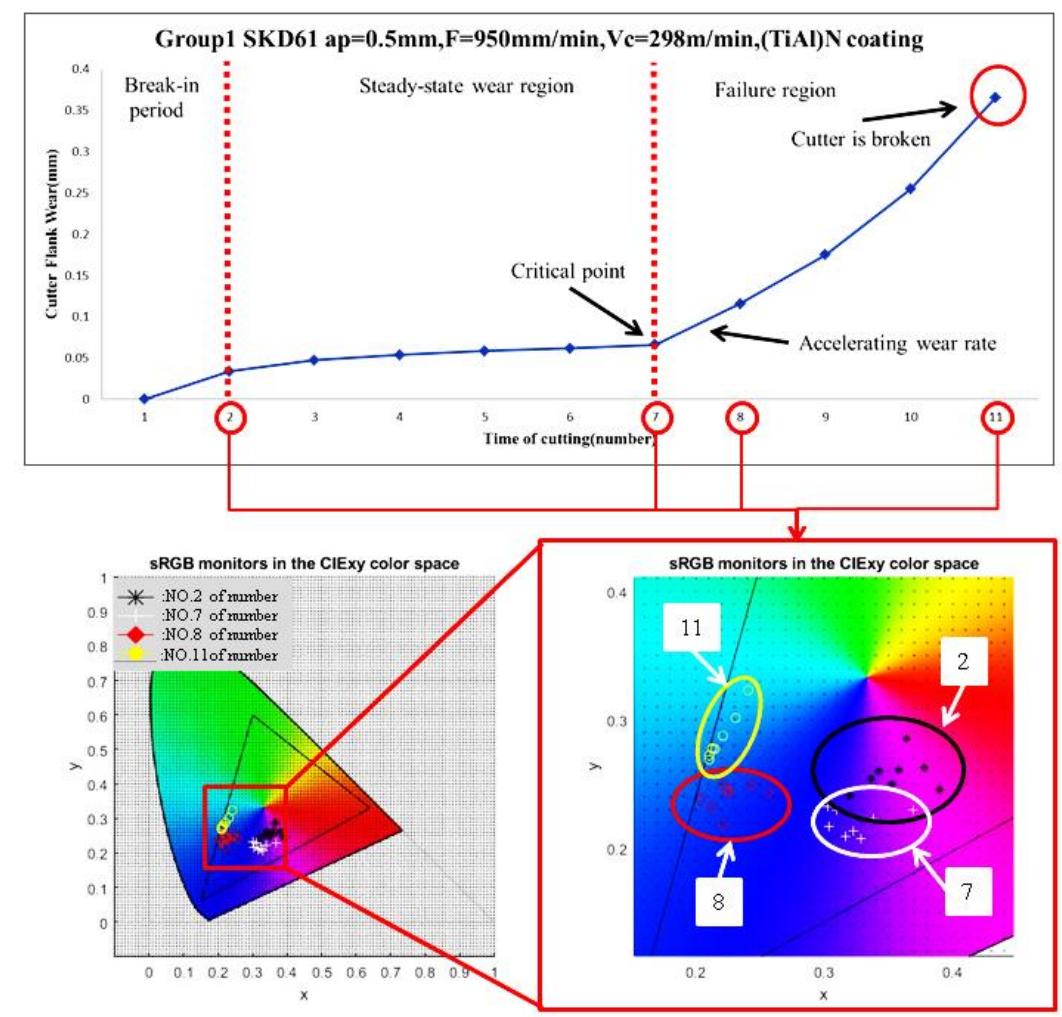

Figure 10. Degree of cutting tool wear and chromaticity coordinate points of TiAlN coating in Group 1 experiment on dry cutting. 


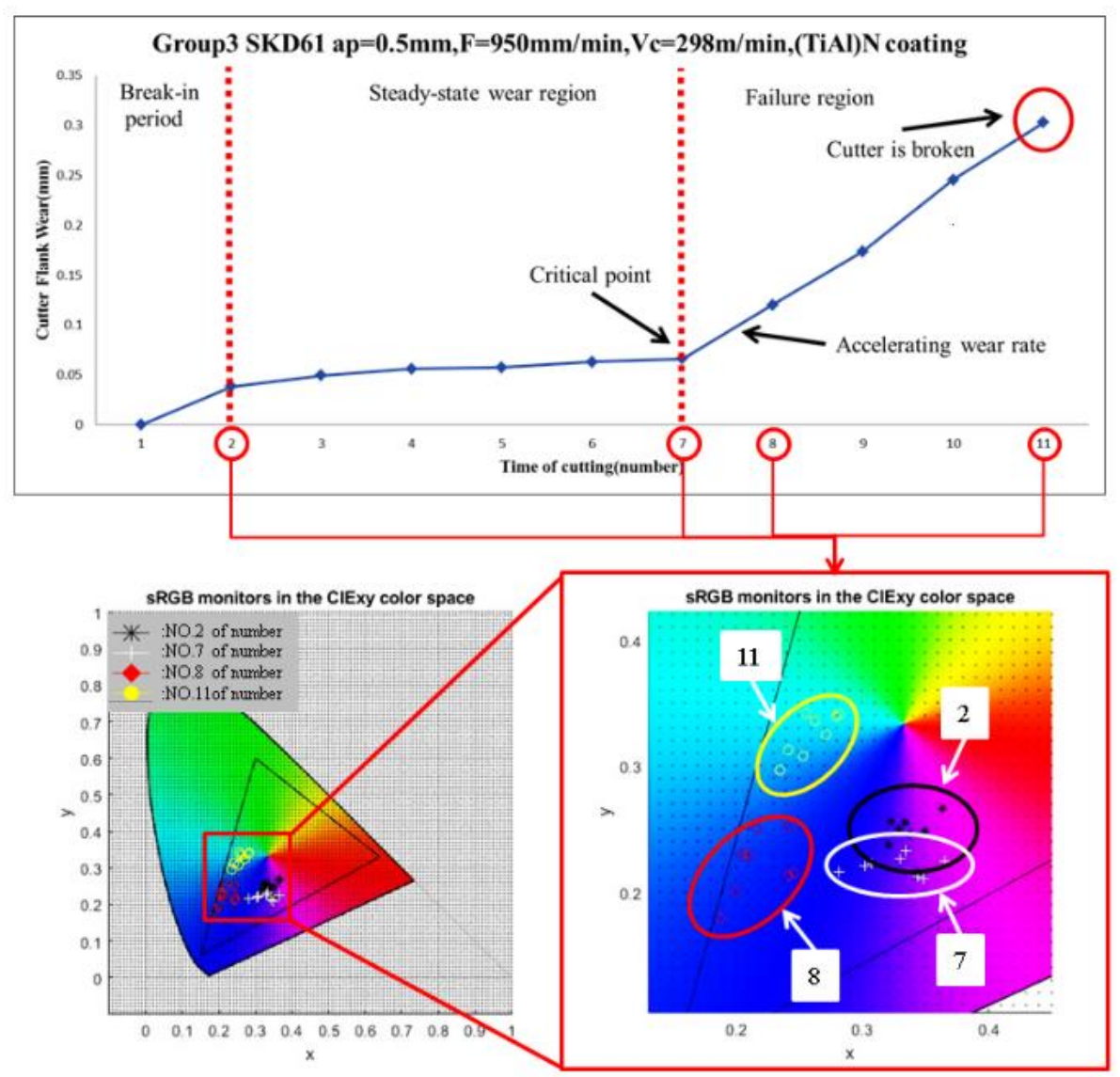

Figure 11. Degree of cutting tool wear and chromaticity coordinate points of TiAlN coating in Group 3 experiment on dry cutting.

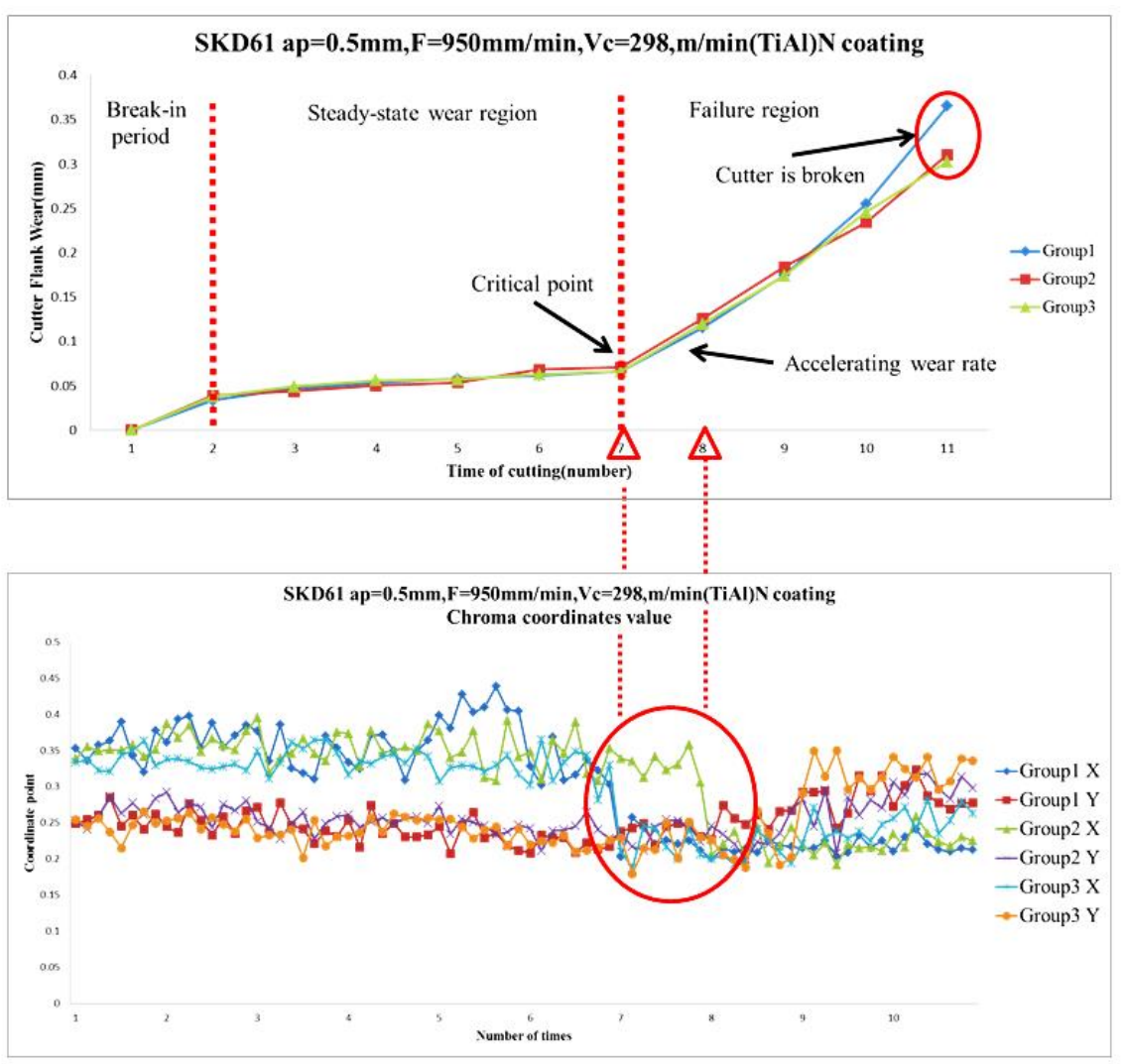


Figure 12. Degree of cutting tool wear and chromaticity coordinate characteristic values of TiAlN coating in three groups of experiments on dry cutting.

\subsection{Test error analysis result of TiAlN cutting tool wear prediction model}

This study performed three sets of repeated cutting tests. Each group has 10 cuttings. Each characteristic value has 80 data points, and 50 data thereof are used for training, and 30 data are used for test, so as to confirm the accuracy of the cutting tool wear prediction model built in this study. The analysis result of BP-LM and GRNN neural network models is divided into three parts to work out the MAPE error value between the model prediction value and actual cutting tool wear loss. Part 1, the measured voltage signal characteristic is used as the input layer of neural network. Part 2, the measured vibration signal characteristic is used as the input layer of neural network. Part 3, the characteristic values of voltage and vibration signals are combined with the chip surface chromaticity eigenvalue as the input layer of neural network. The errors between the prediction values of six groups of machining experiments and the actual cutting tool wear values are discussed below, as shown in Error! Reference source not found.13 14. This study used BP-LM neural network model to predict the cutting tool wear value. Part 1 uses voltage signal characteristic value as input layer, the prediction result of cutting tool wear value is shown in Error! Reference source not found. 3 , and the percentage errors of MAPE are 10.87\%, $6.6 \%$ and $19.37 \%$. Therefore, it is observed when the voltage signal characteristic value is used as input feature, the tool wear trend can be estimated preliminarily, but there are still obvious errors. Part 2 uses vibration signal characteristic value as input layer, the cutting tool wear value prediction result shows that the percentage errors of MAPE are $9.44 \%$, $14.82 \%$ and $9.89 \%$. According to the prediction result, the vibration signal characteristic value for predicting cutting tool wear value has better result than the voltage signal characteristic value. Part 3 combines the characteristic value of vibration signal, characteristic value of voltage signal and characteristic value of chip surface chromaticity. The cutting tool wear value prediction result shows that the percentage errors of MAPE are $8.69 \%$, $7.52 \%$ and $7.34 \%$. When the characteristic value of chip surface chromaticity is added in the prediction result, the cutting tool wear value can be predicted more accurately than single sensor signal characteristic value.

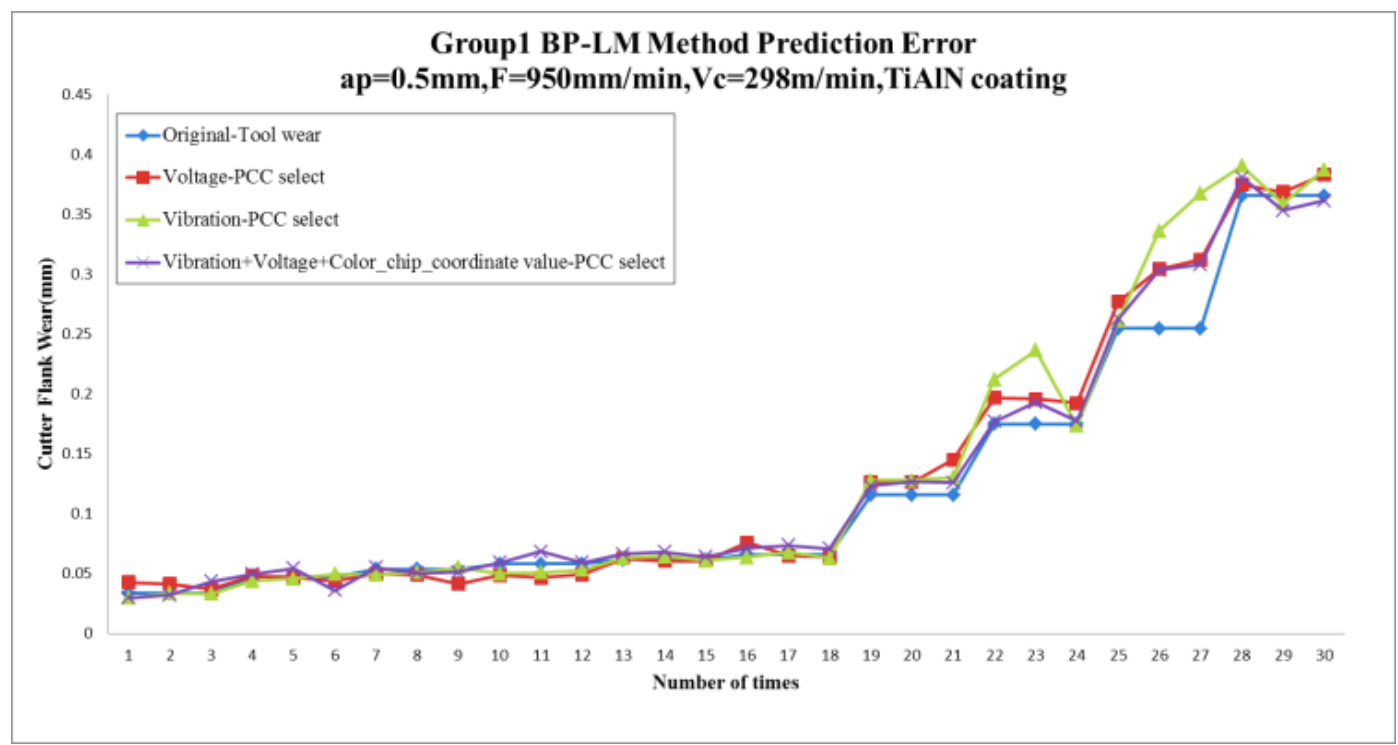

Figure 13. Group 1 cutting tool wear prediction result of TiAlN coating in BP-LM prediction model.

Table 2. Group 1 cutting tool wear prediction error percentage of TiAlN coating in BP-LM prediction model. 


\begin{tabular}{|c|l|l|}
\hline \multicolumn{3}{|c|}{ Group1 BP-LM Method prediction Tool Wear } \\
\hline Sensor selection & PCC Select & MAPE(\%) \\
\hline Voltage & YES & $10.87 \%$ \\
\hline Vibration & YES & $9.44 \%$ \\
\hline Vibration+Voltage+Color_chip_coordinate value & YES & $8.69 \%$ \\
\hline
\end{tabular}

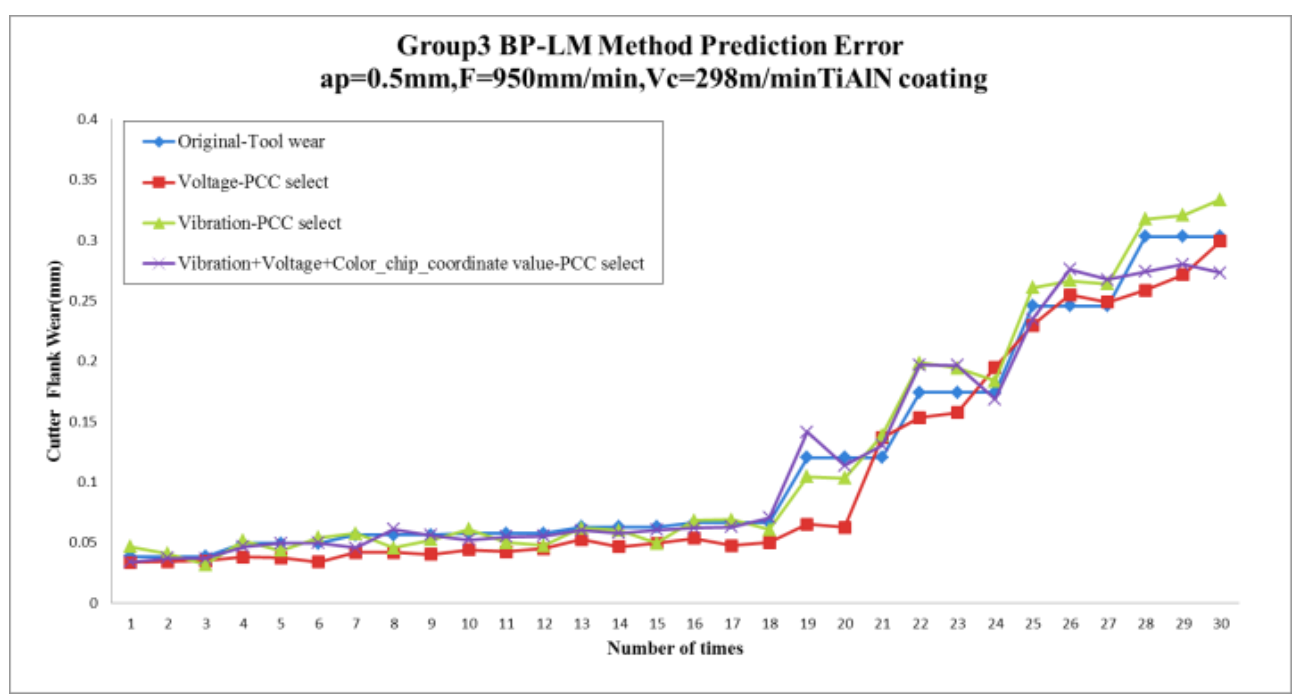

Figure 14. Group 3 cutting tool wear prediction result of TiAlN coating in BP-LM prediction model.

Table 3. Group 3 cutting tool wear prediction error percentage of TiAlN coating in BP-LM prediction model.

\begin{tabular}{|c|l|l|}
\hline \multicolumn{3}{|c|}{ Group3 BP-LM Method prediction Tool Wear } \\
\hline Sensor selection & PCC Select & MAPE(\%) \\
\hline Voltage & YES & $19.37 \%$ \\
\hline Vibration & YES & $9.89 \%$ \\
\hline Vibration+Voltage+Color_chip_coordinate value & YES & $7.34 \%$ \\
\hline
\end{tabular}

Afterwards, this study used GRNN neural network model to predict the cutting tool wear value, as shown in figure 15 16. The first part uses voltage signal characteristic value as input layer, the prediction result of cutting tool wear value is shown in Error! Reference source not found. 5, and the percentage errors of MAPE are $10.35 \%, 8.95 \%$ and $12.93 \%$. Therefore, it is observed when the voltage signal characteristic value is used as input feature, the tool wear trend can be estimated preliminarily, but there are still obvious errors. Part 2 uses vibration signal characteristic value as input layer, the cutting tool wear value prediction result shows that the percentage errors of MAPE are $8.59 \%, 8.04 \%$ and $7.27 \%$. According to the prediction result, the vibration signal characteristic value for predicting the cutting tool wear value has better result than the voltage signal characteristic value. Part 3 combines the characteristic value of vibration signal, characteristic value of voltage signal and characteristic value of chip surface chromaticity. The cutting tool wear value prediction result shows that the percentage errors of MAPE are $7.38 \%, 7.3 \%$ and $5.09 \%$, and after the characteristic value of chip surface chromaticity is added in the prediction result, the cutting tool wear value can be predicted more accurately than single sensor signal characteristic value. 


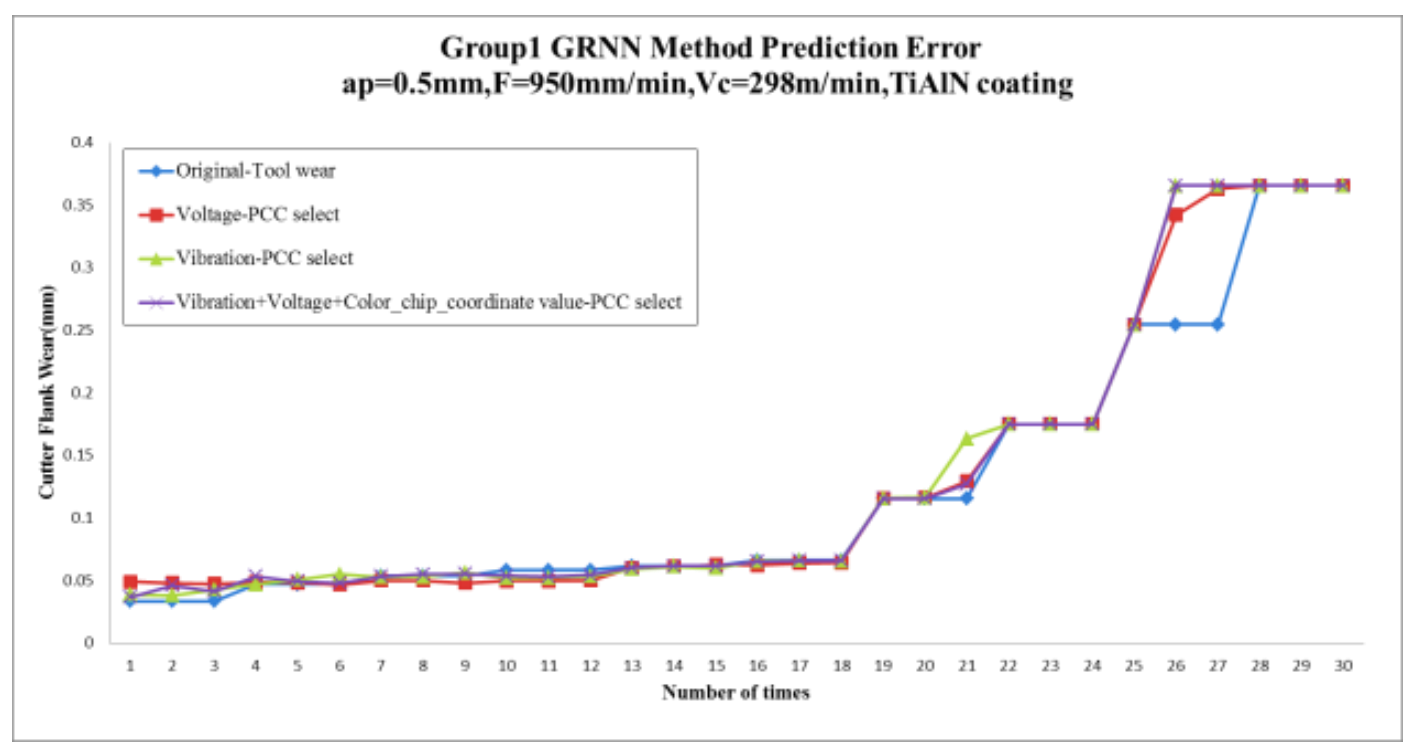

Figure 15. Group 1 cutting tool wear prediction result of TiAlN coating in GRNN prediction model.

Table 4. Group 1 cutting tool wear prediction error percentage of TiAlN coating in GRNN prediction model.

\begin{tabular}{|c|l|l|}
\hline \multicolumn{3}{|c|}{ Group1 GRNN Method prediction Tool Wear } \\
\hline Sensor selection & PCC Select & MAPE(\%) \\
\hline Voltage & YES & $10.35 \%$ \\
\hline Vibration & YES & $8.59 \%$ \\
\hline Vibration+Voltage+Color_chip_coordinate value & YES & $7.38 \%$ \\
\hline
\end{tabular}

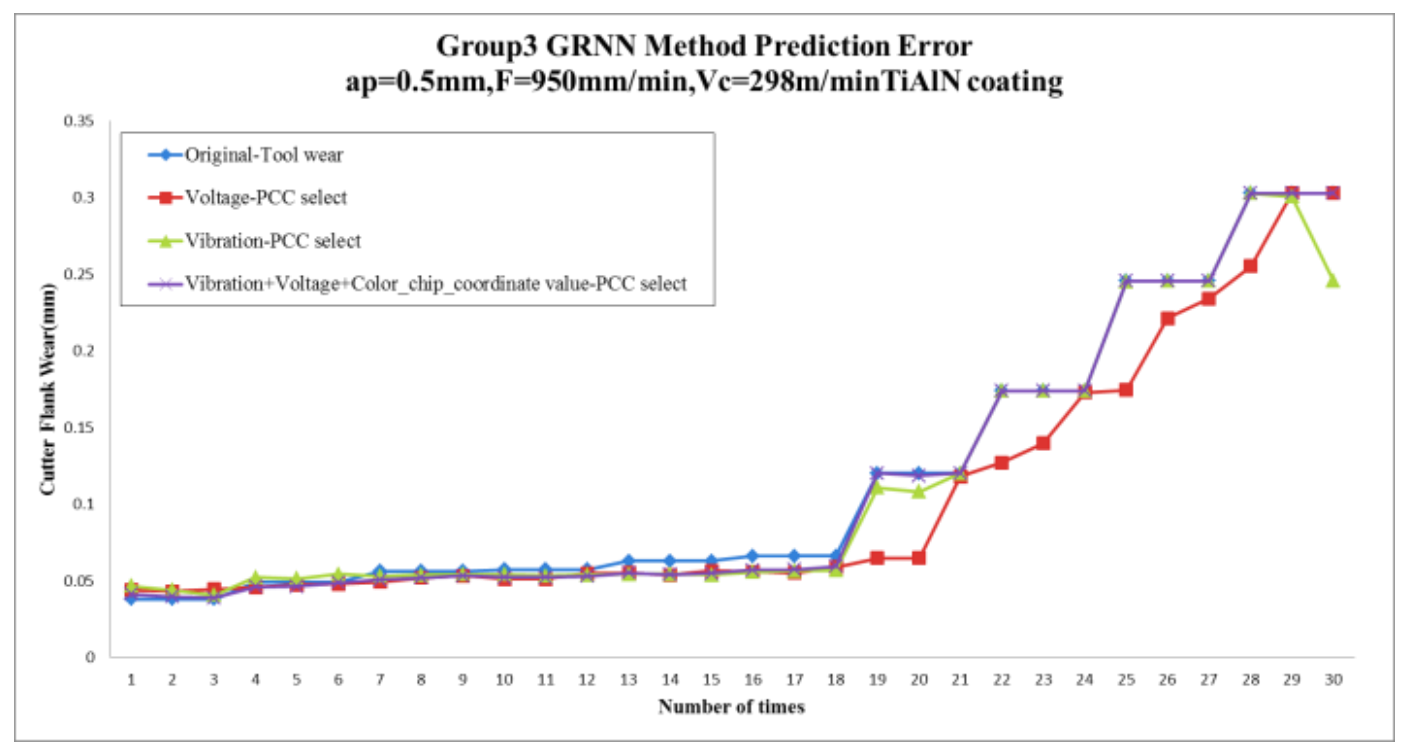

Figure 16. Group 3 cutting tool wear prediction result of TiAlN coating in GRNN prediction model.

Table 5. Group 3 cutting tool wear prediction error percentage of TiAIN coating in GRNN prediction model. 


\begin{tabular}{|c|l|l|}
\hline \multicolumn{3}{|c|}{ Group3 GRNN Method prediction Tool Wear } \\
\hline Sensor selection & PCC Select & MAPE(\%) \\
\hline Voltage & YES & $12.93 \%$ \\
\hline Vibration & YES & $7.27 \%$ \\
\hline Vibration+Voltage+Color_chip_coordinate value & YES & $5.09 \%$ \\
\hline
\end{tabular}

This experiment, the results of three cutting groups are analyzed by using BP-LM and GRNN neural network models. The characteristic value of vibration signal, characteristic value of voltage signal and characteristic value of chip surface chromaticity are combined to discuss the MAPE error value between model prediction value and actual cutting tool wear loss, as shown in Error! Reference source not found.6. The average value of prediction error of BP-LM method is $7.85 \%$, the average value of prediction error of GRNN is $6.59 \%$. According to the accuracy of prediction error proposed, the BP-LM and GRNN prediction methods are in the error range of $\mathrm{MAPE}<10 \%$, representing high precision forecast ability.

Table 6. Cutting tool wear prediction percentage errors of BP-LM and GRNN methods for three cutting groups of TiAlN coating.

\begin{tabular}{|c|c|c|}
\hline \multicolumn{3}{|c|}{ TiAIN-Tool Wear Prediction Error } \\
\hline Number of cutting groups & BP-LM Method MAPE(\%) & GRNN Method MAPE(\%) \\
\hline Group1 & 8.69 & 7.38 \\
\hline Group2 & 7.52 & 7.3 \\
\hline Group3 & 7.34 & 5.09 \\
\hline
\end{tabular}

\section{Conclusion}

After this system is built, as long as the chips are filmed and the cutting time is imported, the industrial circles can be provided with a simple and rapid cutting tool wear identification method. The following conclusions are derived from experiments.

1. Without color correction, as this system is free of standards, it cannot be shared with other filming systems or evaluate color reproducibility. The color correction model of this study can reduce the color difference from $\Delta \mathrm{E}_{\mathrm{ab}}^{*}=18.6$ to 2.94 , the rate of improvement is $84.19 \%$.

2. This experiment used correlation characteristic value selection, calculates different characteristic sets according to the correlation, and the correlation coefficient thresholds higher than 0.9 and higher than -0.9 are selected as key characteristic value, the signal characteristic value of TiAIN coated tips decreases from 51 high dimensional characteristic sets to 23 dimensions, the high dimensional complex operation can be solved, and the prediction result is effective and reliable.

3. The TiAlN coated cutting tool wear value is predicted, the data analysis result shows that the average percentage error of MAPE is $10 \%$ when single vibration and voltage eigenvalues are used as input features, the voltage signal characteristic value, vibration signal characteristic value and chip surface chromaticity characteristic value are combined. The average prediction error of BP-LM method is $7.85 \%$, the average prediction error of GRNN method is $6.59 \%$. Therefore, when the characteristic value of chip surface chromaticity is added in the prediction result, the cutting tool wear value prediction accuracy can be enhanced more effectively than single sensor signal characteristic value.

4. The correlation between TiAlN carbide blade wear and chip surface chromaticity eigenvalue, as the cutting tool wear increases, the trend of chip surface color is purple $\rightarrow$ purple blue $\rightarrow$ blue $\rightarrow$ cyan, even green and yellow ranges, and when the cutting tool is in the accelerating wear phase, the trend of color change is the most obvious. 
1. N.H.A. Halim, C.H.C. Haron, J.A. Ghani, M.F. Azhar, (2019), “Tool wear and chip morphology in high-speed milling of hardened Inconel718 under dry and cryogenic CO2 conditions", Wear 426-427, pp.1683-1690.

2. Ihsan Korkut, Mehmet Boy, Ismail Karacan, Ulvi Seker, 2007, “Investigation of chip-back temperature during machining dependingon cutting parameters", Materials and Design, Vol.28, p.2329-2335.

3. Li Xinwu, (2008), "A Color Error Correction Mode for Digital Camera Based on Polynomial Curve Generation", ISECS International Colloquium on Computing, Communication, Control, and Management, pp.458-461.

4. Hwa-Young Kim, Jung-Hwan Ahn, (2002), “Chip disposal state monitoring in drilling using neural network based spindle motor power sensing", International Journal of Machine Tools \& Manufacture 42, pp.1113-1119.

5. Sudhansu Ranjan Das, Asutosh Panda, Debabrata Dhupal, (2018), “Hard turning of AISI 4340 steel using coated carbide insert: Surface roughness, tool wear, chip morphology and cost estimation", Materials Today, Vol. 5, p.6560-6569.

6. Yuan Ning, M Rahman and Y.S Wong, (2001), "Investigation of chip formation in high speed end milling", Journal of Materials Processing Technology Vol.113, Issues 1-3, p.360-367.

7. S. M. Wu, D. S. Ermer, W. J. Hill, (1966), An Exploratory Study of Taylor's Tool-Life Equation by Power Transformations,J. Eng. Ind. , 88(1): 81-89. https://doi.org/10.1115/1.3670898(Journal of Manufacturing Science and Engineering)

8. M.Kronenberg, (1970), Replacing the Taylor formula by a new tool life equation, International Journal of Machine Tool Design and Research, Volume 10, Issue 2, 193-202.

9. Buderus corporation, (2004), Handbook of Plastic mould Steels.

10. 10.M. J. Xu , (2001), New Cutting Technology, Fuhan Press.

11. 11.S. H. Chen, Z. R. Luo, (2020 Apr), Study of Using Cutting Chip Color To the Tool Wear Prediction, The International Journal of Advanced Manufacturing Technology,Accepted

12. Mitsubishi Tool Co., Ltd., catalog of cutting tools, technical information.

13. S. H. Chen, M. S. Gao, (2019), Study on the Influence of Multi-Sensor and Chip Characteristics Fusion on Tool Life, Master Thesis, National Chin-Yi University of Technology, Taichung County, Taiwan.

14. S. Chinchanikar, S. K. Choudhury, (2015), Machining of hardened steel-experimental investigations, performance modeling and cooling techniques: a review, Int J Mach Tool Manu, vfol. 89, pp 95-109,

15. A. E. Diniz, A. R. Machado, J. G. Corrêa, (2016), Tool wear mechanisms -in the machining of steels and stainless steels, Int J Adv Manuf Technol - Springer, vol. 87, pp 3157-3168

16. S. Zhang, J. F. Li, J. X. Deng and Y. S. Li, (2009), “Investigation on Diffusion Wear During High-Speed Machining Ti-6Al-4V Alloy with Straight Tungsten Carbide Tools,"International Journal of Advanced Manufacturing Technology., vol. 44, no. 1-2, pp. 17-25.

17. S. H. Chen, M. S. Gao, (2019), Method for predicting tool wear with chip color, I649551, Patent, Taiwan. 